\title{
Analysis of calibration results from cup and propeller anemometers. Influence on wind turbine Annual Energy Production (AEP) calculations
}

\author{
Santiago Pindado, ${ }^{1}$ Enrique Vega, ${ }^{1}$ Alejandro Martínez, ${ }^{1}$ Encarnación Meseguer, \\ Sebastián Franchini ${ }^{1}$ and Imanol Pérez Sarasola ${ }^{2}$
}

\begin{abstract}
The calibration coefficients of several models of cup and propeller anemometers were analysed. The analysis was based on a series of laboratory calibrations between January 2003 and August 2007. Mean and standard deviation values of calibration coefficients from the anemometers studied were included. Two calibration procedures were used and compared. In the first, recommended by the Measuring Network of Wind Energy Institutes (MEASNET), 13 measurement points were taken over a wind speed range of 4 to $16 \mathrm{~m} \mathrm{~s}^{-1}$. In the second procedure, 9 measurement points were taken over a wider speed range of 4 to $23 \mathrm{~m} \mathrm{~s}^{-1}$. Results indicated no significant differences between the two calibration procedures applied to the same anemometer in terms of measured wind speed and wind turbines' Annual Energy Production (AEP). The influence of the cup anemometers' design on the calibration coefficients was also analysed. The results revealed that the slope of the calibration curve, if based on the rotation frequency and not the anemometer's output frequency, seemed to depend on the cup center rotation radius. Copyright (C) 2010 John Wiley \& Sons, Ltd.
\end{abstract}

\section{KEYWORDS}

anemometer calibration; cup anemometer; propeller anemometer; MEASNET; annual energy production; AEP

\section{Correspondence}

Santiago Pindado, Universidad Politécnica de Madrid, ETSI Aeronáuticos, Instituto Universitario de Microgravedad 'Ignacio Da Riva' (IDR/UPM), Madrid, Spain.

E-mail: santiago.pindado@upm.es

Received 21 May 2009; Revised 15 March 2010; Accepted 13 April 2010

\section{INTRODUCTION}

Nowadays, the use of anemometers is increasing as a result of the growing importance of wind as an energy source. ${ }^{1}$ Among the different types of anemometers used to measure wind speed, cup and propeller anemometers are the most common after considering all of the possible applications. Both kinds of anemometers are easy to operate and, in general, provide sufficiently accurate wind speed measurements.

Leaving aside some particular problems of cup and propeller anemometers when used in turbulent flows (e.g. overspeeding), ${ }^{2,3}$ it can be said that a properly calibrated anemometer will provide good measurements of the wind speed (horizontal component of the wind). This is extremely important to the energy industry, as wind energy is proportional to the third power of the wind speed. ${ }^{1,4}$

The calibration method used involves placing the anemometer in an incoming flow with a known speed, uniformity and turbulence level provided by the test chamber of a high-quality wind tunnel, and measuring the output signal of the anemometer at various given wind speeds. Instituto Universitario de Microgravedad 'Ignacio Da Riva' (IDR/UPM Institute) is a Spanish Measuring Network of Wind Energy Institutes (MEASNET) center recognized for anemometer calibration. Between 1998 and 2007, several thousands of calibrations were performed at this research center as industry demand has been increasing steadily in recent years. As a member of MEASNET, the calibrations carried out at the IDR/UPM 


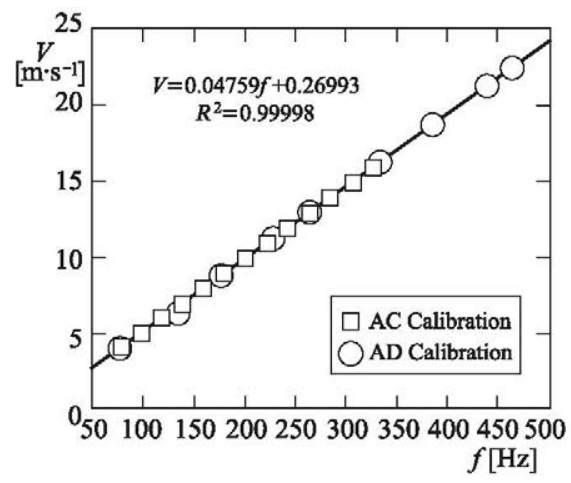

Figure 1. Example of the results from two calibrations performed on the same cup anemometer (Thies 4.3350) following different procedures ( $A C$ and $A D$, as explained in the text). The wind speed measured by the wind tunnel instruments $V$ is plotted in comparison to the anemometer's frequency output $f$. The regression line corresponding to the $\mathrm{AC}$ calibration is also displayed in the insert.

Institute are performed following precise, specific procedures to ensure a high level of accuracy. Among the requirements fulfilled by the IDR/UPM Institute are: ${ }^{5}$

- All transducers and measuring equipment have traceable calibrations.

- Prior to every calibration round, the integrity of the experimental set-up is verified.

- Flow quality measurement is carried out periodically.

- The repeatability of the calibration is verified periodically.

- Anemometer calibration is supported by a detailed assessment of calibration uncertainty.

- IDR/UPM Institute is accredited in accordance with the UNE EN-ISO/IEC 17025 (Spanish acronym for the European ISO/IEC 17025 standard) quality assurance procedure as a calibration lab for fluid velocity measurements.

To emphasize the quality of the data studied in the present work, it should also be mentioned that the IDR/UPM Institute obtained good results in the latest MEASNET Round Robin evaluations, performed during 2000, 2003 and 2005. A Round Robin test is an intercomparison exercise of calibrations from a set of cup anemometers operated by all MEASNET members conducting anemometer calibrations (at the time of this writing, these members are Deutsches Windenergie-Institut (DEWI), Greek Centre for Renewable Energy Sources (CRES), IDR/UPM, Wind Consult, Svend Ole Hansen Aps and Ingenieurburo Dr. In. Dieter Frey). An individual MEASNET member passes the test if its result (the output frequency measured at a specific wind speed) deviates less than $1 \%$ with respect to the mean value calculated from the results of all members. ${ }^{6}$ If successfully completed, Round Robin testing guarantees wide confidence in the anemometer calibration results, which is required in validation and certification programs concerning wind turbines (e.g. power curve) from one country to another.

A typical calibration curve from a cup anemometer (Thies Clima, Göttingen, Germany 4.3350) is shown in Figure 1. Most calibration procedures specify that the rotation frequency output of the anemometer (or another output variable such as voltage) must be measured at certain specific wind speeds. ${ }^{5}$ As a result, the calibration curve is obtained by performing a linear fitting based on the results:

$$
V=\mathrm{A} \cdot f+\mathrm{B}
$$

where $V$ is the velocity of the flow (wind speed), $f$ is the anemometer's rotation frequency output, and A (slope) and B (offset) are the calibration coefficients corresponding to the tested anemometer. Although the behavior of cup and propeller anemometers is not exactly linear, based on the general experience with steady flows, it can be aptly described for most purposes as a linear fit. ${ }^{2}$

It must be said that the frequency output does not actually correspond to the turning frequency of the anemometer's rotor (the cups or propeller). In fact, the anemometer's frequency output $f$ is the result of multiplying the rotation frequency of the anemometer $f_{r}$ by the number of pulses per revolution given by the anemometer $N_{p}$. Using the anemometer's rotation frequency instead of the frequency output, the expression (1) can be rewritten as:

$$
V=\mathrm{A}_{r} \cdot f_{r}+\mathrm{B}
$$

where $\mathrm{A}_{r}$ is the result of multiplying calibration constant A by the number of pulses given by the anemometer $N_{p}$. The use of $f_{r}$ instead of $f$ has been considered in the analysis because it has a clearer physical meaning, as suggested by some theoretical models. ${ }^{7,8}$ 
Table I. Geometrical characteristics of the anemometers studied, including the cup diameter $D_{c}$, the front area of the cups $S_{0}$ $\left(S_{c}=\pi \times D_{c}^{2} / 4\right)$, the rotor diameter $D_{r}$, the cup center rotation radius $R_{r c}\left[R_{r c}=\left(D_{r}-D_{c}\right) / 2\right]$, the ratio of the rotor diameter to the cup diameter $\phi\left(\phi=D, D_{d}\right)$ and the number of output pulses per revolution given by the anemometer $N_{p}$.

\begin{tabular}{|c|c|c|c|c|c|c|c|}
\hline Anemometer & Type & $D_{c}(\mathrm{~mm})$ & $S_{c}\left(\mathrm{~mm}^{2}\right)$ & $D_{t}(\mathrm{~mm})$ & $R_{r 0}(\mathrm{~mm})$ & $\phi$ & $N_{0}$ \\
\hline $\begin{array}{l}\text { NRG Systems Maximum } \\
40 / 40 \mathrm{C} / 40 \mathrm{H}\end{array}$ & Cups (conical) & 51 & 2043 & 190 & 69.5 & 3.73 & 2 \\
\hline NRG IceFree & Cups (other) & 40 & - & 128 & 44 & 3.20 & 2 \\
\hline RISø P2546A & Cups (conical) & 70 & 3848 & 188 & 59 & 2.69 & 2 \\
\hline Thies 4.3350 & Cups (conical) & 80 & 5027 & 240 & 80 & 3.00 & 37 \\
\hline Thies 4.3303 & Cups (spherical) & 78 & 4778 & 316 & 119 & 4.05 & 44 \\
\hline Thies 4.3520 & Cups (spherical) & 44 & 1521 & 134 & 45 & 3.05 & 10 \\
\hline Thies 4.3324 & Cups (conical) & 78 & 4778 & 316 & 119 & 4.05 & 44 \\
\hline Thies 4.3519 & Cups (conical) & 44 & 1521 & 134 & 45 & 3.05 & 11 \\
\hline Climatronics 100075 & Cups (conical) & 51.5 & 2083 & 190 & 69.25 & 3.69 & 30 \\
\hline $\begin{array}{l}\text { Vector Instruments } \\
\text { A100 L2/K/LK/ } \\
\text { LM/R/M }\end{array}$ & Cups (conical) & 50 & 1964 & 152 & 51 & 3.04 & $\begin{array}{l}25 / 25 / 25 / \\
13 / 1 / 13\end{array}$ \\
\hline Ornytion 107A & Cups (conical) & 50 & 1964 & 156 & 53 & 3.12 & 2 \\
\hline RM Young 3002 & Cups (spherical) & 40 & 1257 & 190 & 75 & 4.75 & 1 \\
\hline RM Young 3102 & Cups (spherical) & 40 & 1257 & 190 & 75 & 4.75 & 1 \\
\hline RM Young 05103 & Propeller & - & - & - & - & - & 3 \\
\hline RM Young $27106 \mathrm{~T}$ & Propeller & - & - & - & - & - & - \\
\hline Vaisala WAA 151/252 & Cups (conical) & 54 & 2290 & 182 & 64 & 3.37 & $14 / 14$ \\
\hline Orbital 420 & Cups (spherical) & 52 & 2124 & 164 & 56 & 3.15 & 6 \\
\hline
\end{tabular}

See also Figure 2.

The aim of this article is to study the values of some cup and propeller anemometers' calibration coefficients A and $\mathrm{B}$, analysing the influence of the anemometer geometry on both coefficients. This study was carried out by postprocessing the anemometers' calibration results obtained at the IDR/UPM Institute in the period from January 2003 to August 2007. The anemometers selected for these statistics (NRG Systems 40/40C/40H/IceFree (NRG Systems, Inc.: Hinesburg, Vermont, USA); Risø P2546 (WindSensor (Risø DTU): Roskilde, Denmark); Thies 4.3350/4.3303/4.3520/4 .3324/4.3519; Climatronics 100075 (Climatronics Corp.: Bohemia, New York, USA); Vector Instruments A100 L2/K/ LK/LM/R/M (Windspeed Limited (trading as Vector Instruments): RHYL, UK); Ornytion 107 (Ornytion: Bergondo, A Coruña, Spain); Vaisala WAA 151/252 (Vaisala Oyj: Helsinki, Finland); Orbital 420 (Orbital A/S: Skjern, Denmark); RM Young 3002/3002VM/3102/3102VM/05103/27106T (R. M. Young Company: Traverse City, Michigan, USA)) are the most frequently calibrated at the IDR/UPM Institute, and represent more than $95 \%$ of the total number of calibrations carried out by the Institute during this period. The geometrical characteristics of the anemometers studied, including the cup diameter $D_{c}$, the front area of the cups $S_{c}\left(S_{c}=\pi \times D_{c}{ }^{2} / 4\right)$, the rotor diameter $D_{r}$, the cup center rotation radius $R_{r c}$ $\left[R_{r c}=\left(D_{r}-D_{c}\right) / 2\right]$, the ratio between the rotor diameter and cup diameter $\phi\left(\phi=D_{r} / D_{c}\right)$ and the number of output pulses per revolution given by the anemometer $N_{p}$ are shown in Table I (see also Figure 2).

The mean and standard deviation values of coefficients A and B included in this article were calculated taking into account only the calibrations performed on new anemometers, i.e. those not yet installed for use.

The information contained in this article should be taken as a reference only. The coefficients included here can never replace the proper calibration of each individual anemometer.

\section{TESTING CONFIGURATION AND CALIBRATION SETUP}

At the IDR/UPM Institute, anemometer calibrations are performed in the S4 wind tunnel (see Figure 3). This facility is an open-circuit wind tunnel with a closed test section measuring 0.9 by $0.9 \mathrm{~m}$. It is served by four $7.5 \mathrm{~kW}$ fans with a flow uniformity under $0.2 \%$ in the testing area. The wind speed in the testing chamber is measured by an Airflow 0.48 Pitot (AIRFLOW Instruments, TSI Instruments Ltd.: Buckinghamshire, UK) tube connected to a Druck LPM 9481 (GE Sensing: Billerica, MA, USA) high-precision pressure transducer, with the electrical signal from the pressure transducer measured by a Keithley 2000 (Keithley Instruments, Inc., Cleveland, Ohio, USA) digital multimeter. Temperature and humidity sensors (Vaisala PTU 200 and Vaisala HMP45D) are used to determine the air density value. The rotation frequency of the anemometer is measured with an Agilent 53131A (Agilent Technologies Inc.: Santa Clara, CA, USA) universal counter. Another digital multimeter is used to measure the voltage or current output from the anemometer when required. 


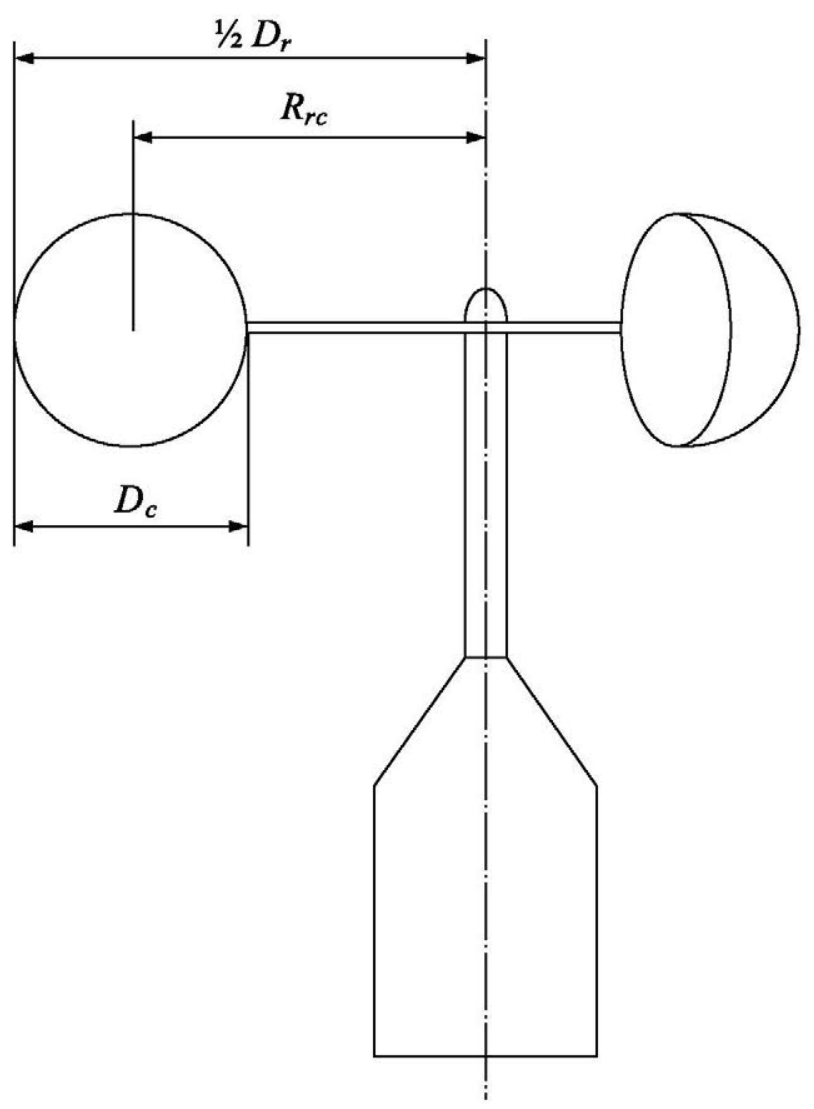

Figure 2. Sketch of the cup anemometer geometry. The cup diameter $D_{c}$ rotor diameter $D_{t}$ and cup center rotation radius $R_{r C}$ are indicated.

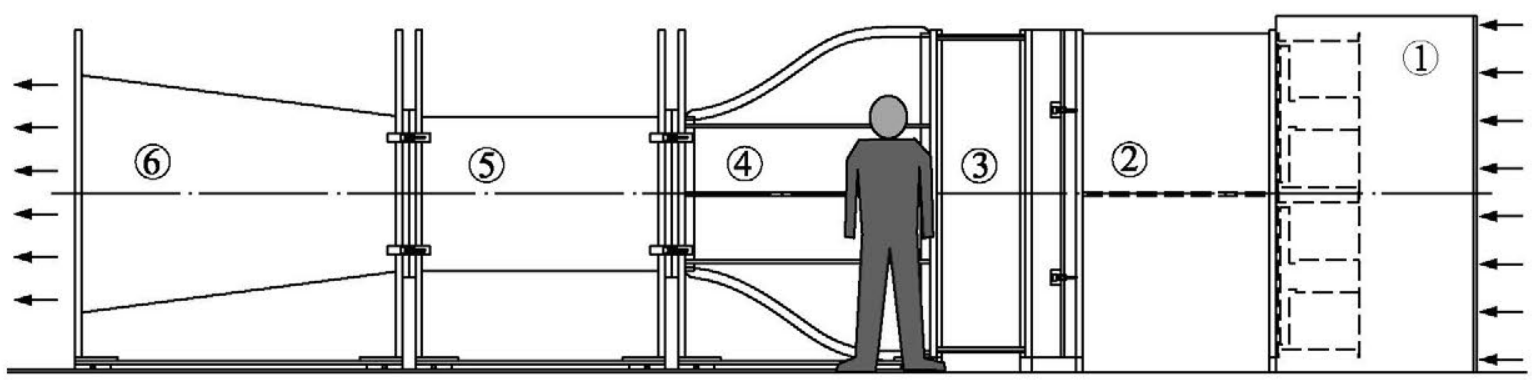

Figure 3. Sketch of the $S 4$ wind tunnel at the IDR/UPM Institute used for anemometer calibration. The different parts of the wind tunnel are indicated in the figure as follows: $1=$ fans; $2=$ plenum chamber; $3=$ honeycomb and grids; $4=$ contraction; $5=$ test chamber; and 6 = diffuser.

\subsection{Comparison of calibration procedures}

Two different anemometer calibration procedures are used by the IDR/UPM Institute depending on the customer's requirements: the $\mathrm{AC}$ calibration procedure and the $\mathrm{AD}$ calibration procedure. The differences between the two procedures are the wind speed range where the calibration is performed, and the number of points taken in that range. AC calibrations strictly adhere to the MEASNET procedure, ${ }^{5}$ i.e. they are carried out for wind speeds ranging from $4 \mathrm{~m} \mathrm{~s}^{-1}$ to $16 \mathrm{~m} \mathrm{~s}^{-1}$ and 13 measurement points are taken. On the other hand, $\mathrm{AD}$ calibrations are carried out over a broader wind speed range, from $4 \mathrm{~m} \mathrm{~s}^{-1}$ to $23 \mathrm{~m} \mathrm{~s}^{-1}$ and 9 measurement points are taken (see an example of both $\mathrm{AC}$ and $\mathrm{AD}$ calibrations in Figure 1). The $\mathrm{AD}$ calibration procedure was designed to meet the requirements of some customers who needed a broader speed range than the one specified by MEASNET, who accepted the slight lack of accuracy in the range from 4 to $16 \mathrm{~m} \mathrm{~s}^{-1}$ that this 
(a)

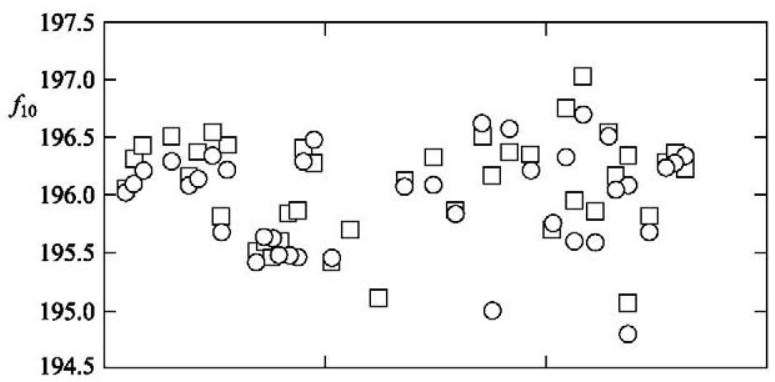

(b)

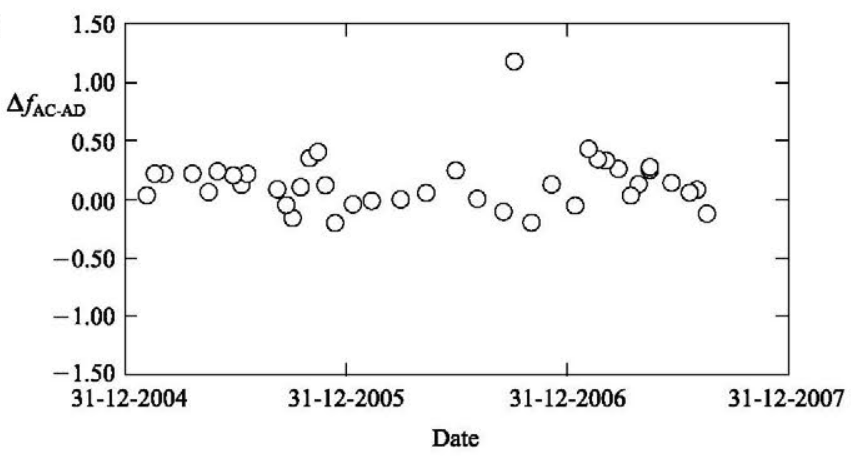

Figure 4. (a) Pairs of output frequencies ( $A C$ and $A D$ calibrations) at $10 \mathrm{~m} \mathrm{~s}^{-1}$ wind speed $f_{10}$ on the IDR/UPM internal procedures anemometer (Vector Instruments A100 L2), from February 4, 2005, to August 16, 2007. (b) Difference between the two frequencies $\Delta f_{A C-A D}$

could represent. Figure 1 shows $\mathrm{AC}$ and $\mathrm{AD}$ calibrations performed on the same anemometer. The $\mathrm{AC}$ calibration curve is $V=0.04759 f+0.26993$, whereas the AD calibration curve is $V=0.04798 f+0.10225$. In both cases, the square of the correlation coefficient between the data and the linear fit $R^{2}$ was higher than 0.99995 . In the period under study, $25 \%$ of the calibrations requested of the IDR/UPM were AD calibrations. This rate has decreased to $10 \%$ in 2008 and 2009.

Let us analyse the influence of the calibration procedure on the Annual Energy Production (AEP) of a wind turbine. According to MEASNET, ${ }^{9}$ in the case of a $2 \mathrm{MW}$ pitch-controlled variable-speed wind turbine placed in a site characterized by a $7 \mathrm{~m} \mathrm{~s}^{-1}$ annual mean wind speed and Rayleigh distribution, 'the wind speed range from 4 to $16 \mathrm{~m} \mathrm{~s}^{-1}$ accounts for $95 \%$ of the annual energy production, while only $4.5 \%$ is produced at higher speeds'. Taking into account that the anemometer's behavior is not exactly linear, MEASNET also strongly suggests that 'the calibration interval must be as narrow as allowed by the specific application of the anemometer'. ${ }^{9}$ For these reasons, MEASNET suggests that the calibration range should not be extended as the gain in accuracy above $16 \mathrm{~m} \mathrm{~s}^{-1}$ would reduce the accuracy in the range where most of the wind energy is concentrated. In some cases, however, an extended wind speed range seems to be required by the industry, based on the anemometer calibrations requested of the IDR/UPM Institute over the past few years.

The comparison between the two procedures described earlier, $\mathrm{AC}$ and $\mathrm{AD}$, can be made because a series of nearly simultaneous $\mathrm{AC}$ and $\mathrm{AD}$ calibrations performed on the same anemometer are available. In Figure 4, the output frequency at a wind speed of $10 \mathrm{~m} \mathrm{~s}^{-1}, f_{10}$, on the IDR/UPM reference anemometer (Vector Instruments A100 L2) is plotted, taking into account the different calibrations performed because of internal verifications during the period considered. This internal procedure periodically requires two consecutive calibrations, one $\mathrm{AC}$ and one $\mathrm{AD}$, of the reference anemometer. The data plotted in Figure 4 therefore shows pairs of frequencies related to both calibration procedures. The difference between frequencies $\Delta f_{\mathrm{AC}-\mathrm{AD}}$, corresponding to each pair of calibrations for the aforementioned wind speed, is also plotted in Figure 4.

If we assume that the differences mentioned are the result of a Gaussian process, it could be said that the output frequency deviation $\Delta f_{\mathrm{AC}-\mathrm{AD}}$ at a wind speed of $10 \mathrm{~m} \mathrm{~s}^{-1}$ will be in the range from -0.17 to $0.4 \mathrm{~Hz}$ with a $90 \%$ confidence level (see Figure 5). As a result, at that reference wind speed, the $90 \%$ confidence error from using an $\mathrm{AD}$ calibration rather than the AC calibration (the optimum one as stated by MEASNET) will be from $-0.09 \%$ to $0.20 \%$ in terms of wind speed (calculated as calibration parameter $\mathrm{A}$ from the $\mathrm{AC}$ calibration, multiplied by $\Delta f_{\mathrm{AC}-\mathrm{AD}}$ ). Table II shows the $90 \%$ confidence error limits regarding frequency deviation $\Delta f_{\mathrm{AC}-\mathrm{AD}}$ and wind speed when using an $\mathrm{AD}$ calibration rather than an AC calibration for some reference wind speeds.

With the measured wind speed differences calculated earlier, the effect of using the IDR/UPM reference anemometer with an $\mathrm{AD}$ rather than an $\mathrm{AC}$ calibration on the $\mathrm{AEP}$ of a wind turbine has been analysed. Figure 6 shows the power 


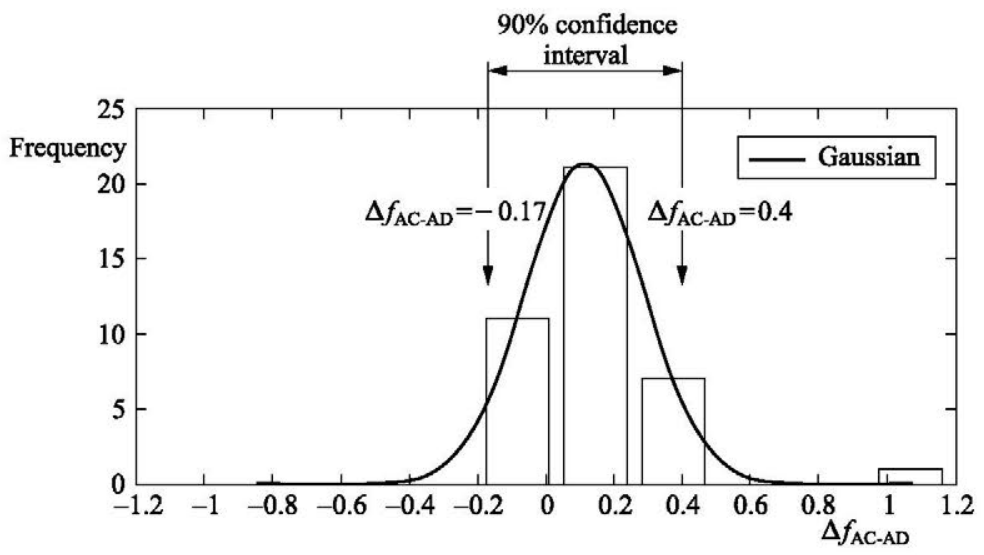

Figure 5. Frequency histogram corresponding to the difference in output frequency between $A C$ and $A D$ calibrations performed on the IDR/UPM reference anemometer (Vector Instruments A100 L2) between February 4, 2005 and August 16, 2007 at a wind speed of $10 \mathrm{~m} \mathrm{~s}^{-1}$.

Table II. $90 \%$ confidence error limits in frequency deviation $\Delta f_{A C-A D}$ and measured wind speed $V_{A D}$ when using an $A D$ calibration rather than an AC calibration with respect to the IDR/UPM reference anemometer (Vector Instruments A100 L2).

\begin{tabular}{|c|c|c|c|c|}
\hline \multirow[t]{2}{*}{ Reference wind speed $\left(\mathrm{m} \mathrm{s}^{-1}\right)$} & \multicolumn{2}{|c|}{$\Delta f_{A C-A D}(\mathrm{~Hz})$} & \multicolumn{2}{|c|}{$V_{A D}\left(\mathrm{~ms}^{-1}\right)$} \\
\hline & Lower limit & Upper limit & Lower limit (\%) & Upper limit (\%) \\
\hline 4 & -0.424 & 0.324 & $3.979(-0.5)$ & $4.016(+0.4)$ \\
\hline 5 & -0.371 & 0.338 & $4.981(-0.4)$ & $5.017(+0.3)$ \\
\hline 6 & -0.253 & 0.261 & $5.987(-0.2)$ & $6.013(+0.2)$ \\
\hline 8 & -0.201 & 0.251 & $7.990(-0.1)$ & $8.013(+0.2)$ \\
\hline 10 & -0.17 & 0.400 & $9.991(-0.1)$ & $10.020(+0.2)$ \\
\hline 12 & -0.219 & 0.525 & $11.989(-0.1)$ & $12.026(+0.2)$ \\
\hline 14 & -0.260 & 0.574 & $13.987(-0.1)$ & $14.029(+0.2)$ \\
\hline 16 & -0.223 & 0.714 & $15.989(-0.1)$ & $16.036(+0.2)$ \\
\hline 18 & -0.313 & 0.955 & $17.984(-0.1)$ & $18.048(+0.3)$ \\
\hline 20 & -0.422 & 1.178 & $19.979(-0.1)$ & $20.059(+0.3)$ \\
\hline 22 & -0.401 & 1.308 & $21.980(-0.1)$ & $22.065(+0.3)$ \\
\hline 24 & -0.555 & 1.613 & $23.972(-0.1)$ & $24.081(+0.3)$ \\
\hline
\end{tabular}

Percentage deviation in wind speed in parentheses.

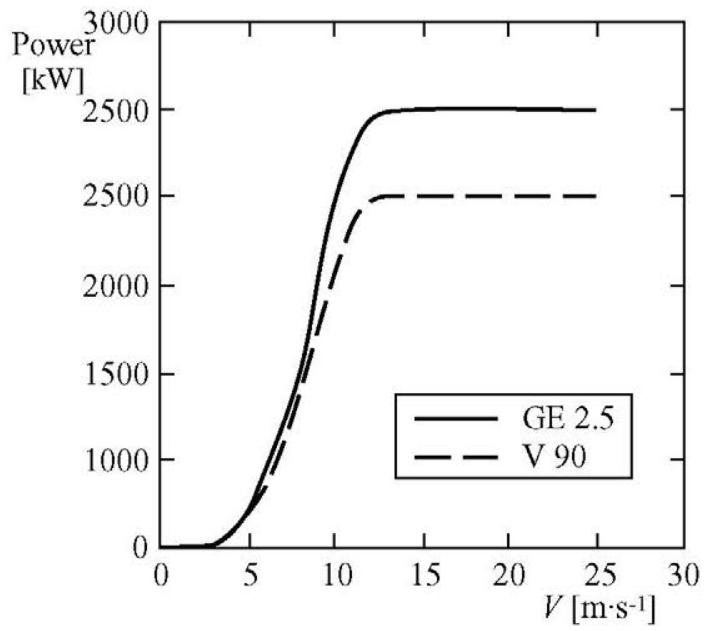

Figure 6. Power curves for General Electric GE2.5 and Vestas V90 wind turbines. 
Table III. 90\% confidence error limits in AEP on General Electric GE2.5 and Vestas V90 wind turbines when using an AD calibration rather than an AC calibration with respect to the IDR/UPM reference anemometer (Vector Instruments A100 L2).

\begin{tabular}{|c|c|c|c|c|}
\hline \multirow[t]{2}{*}{ Annual average wind speed $\left(\mathrm{m} \mathrm{s}^{-1}\right)$} & \multicolumn{2}{|c|}{ GE2.5 $90 \%$ confidence AEP deviation } & \multicolumn{2}{|c|}{ VE90 $90 \%$ confidence AEP deviation } \\
\hline & Lower limit (\%) & Upper limit (\%) & Lower limit (\%) & Upper limit (\%) \\
\hline 4 & -0.80 & 0.91 & -0.79 & 0.88 \\
\hline 5 & -0.57 & 0.65 & -0.56 & 0.63 \\
\hline 6 & -0.42 & 0.49 & -0.42 & 0.47 \\
\hline 7 & -0.32 & 0.38 & -0.32 & 0.37 \\
\hline 8 & -0.26 & 0.30 & -0.25 & 0.29 \\
\hline 9 & -0.21 & 0.24 & -0.21 & 0.24 \\
\hline 10 & -0.17 & 0.20 & -0.17 & 0.20 \\
\hline 11 & -0.15 & 0.17 & -0.14 & 0.17 \\
\hline
\end{tabular}

curves from two wind turbines (General Electric GE2.5 (GE Sales and Service Headquarters: Jenbach, Austria) and Vestas V90 (Vestas Wind Systems A/S: Randers, Denmark)). Following the procedure recommended by the International Electrotechnical Commission (IEC), ${ }^{10}$ the $90 \%$ confidence error limits of the AEP corresponding to the GE2.5 and V90 wind turbines have been calculated with the velocity deviations in Table II. These AEP percentage deviations for hub height annual average wind speeds of 4, 5, 6, 7, 8, 9, 10 and $11 \mathrm{~m} \mathrm{~s}^{-1}$ are shown in Table III.

Taking into account these results, the AEP estimation error when using the IDR/UPM reference anemometer with an $\mathrm{AD}$ calibration is around $0.6-0.9 \%$ for low annual average wind speeds $\left(4-5 \mathrm{~m} \mathrm{~s}^{-1}\right)$ and $0.2 \%$ for high annual average wind speeds $\left(10-11 \mathrm{~m} \mathrm{~s}^{-1}\right)$. These errors are similar to the examples of uncertainties related to instruments and data acquisition systems contained in the procedure recommended by the IEC. ${ }^{10}$

\section{RESULTS AND DISCUSSION}

The results concerning historical records of $\mathrm{AC}$ and $\mathrm{AD}$ calibrations are shown, respectively, in Tables IV and V. In every case, the mean and standard deviations of A and B coefficients [see expression (1) and Figure 1] were calculated taking into account only those tests where the square of the correlation coefficient between the data and the linear fit $R^{2}$ was over 0.99995 . The only exception to this rule is the NRG IceFree anemometer for which coefficients were calculated taking into account tests where $R^{2}>0.999$. This model, designed for icing environments, has displayed special behavior at low wind speeds in tests performed at the IDR/UPM, the starting speed being dependent on the wind direction. In Figure 7, the unique shape of this anemometer can be appreciated when compared with a more standard one (Thies 4.3350).

Using the mean values of the calibration coefficients included in Tables IV and V, the difference between output frequencies from both $\mathrm{AC}$ and $\mathrm{AD}$ procedures $\Delta f_{\mathrm{AC}-\mathrm{AD}}$ has been calculated for reference wind speeds. Using these values, the error in terms of wind speed has also been calculated as $\mathrm{A}_{\mathrm{AC}}$ multiplied by $\Delta f_{\mathrm{AC}-\mathrm{AD}}$, where $\mathrm{A}_{\mathrm{AC}}$ is the $\mathrm{A}$-calibration parameter from the $\mathrm{AC}$ calibration. In Table VI, the percentage variation in wind speed resulting from using an $\mathrm{AD}$ calibration rather than an $\mathrm{AC}$ calibration is included for several anemometers at reference wind speeds. Only anemometers that had been calibrated at least 10 times were considered. The calculated values corresponding to the IDR/ UPM Institute reference anemometer (the upper limit in Table II) were also included.

Although the differences in measured wind speeds do not seem large from one calibration procedure to the other, the percentage variation in the AEP of a GE2.5 wind turbine resulting from those differences has been calculated for the selected anemometers to provide a better comparison of the two procedures. Table VII shows these differences for three different hub height annual average wind speeds, 4, 7 and $10 \mathrm{~m} \mathrm{~s}^{-1}$. For most of the selected anemometers, the results show no major differences in the AEP from one anemometer calibration procedure to another. The largest differences are observed in the case of the NRG IceFree anemometer. This is not surprising as this is a special anemometer that required less precision in the calibration procedure as explained earlier. Finally, it should be mentioned that the results for the Vector Instruments A100 L2 are consistent with those calculated using more solid statistics for the IDR/UPM reference anemometer in section 2 of this article.

In Figure 8, the values of coefficient $\mathrm{A}$ in $\mathrm{AC}$ calibrations of cup anemometers (frequency output) are plotted as a function of the rotor diameter $D_{r}$ and cup diameter $D_{c}$. A-coefficient values seem to be concentrated in two horizontal bands. The higher one, from $\mathrm{A}=0.6$ to $1.22 \mathrm{~m} \mathrm{~s}^{-1}$ per $\mathrm{Hz}$, corresponds to anemometers that give one or two pulses per revolution, and the lower one, from $\mathrm{A}=0.045$ to $0.2 \mathrm{~m} \mathrm{~s}^{-1}$ per $\mathrm{Hz}$, includes anemometers that give more than six pulses per revolution. Anemometers with A-coefficient values in the higher band generate the output frequency with magnet systems (sinusoidal output wave), whereas those with A-coefficient values in the lower band generate the output 
Table IV. Mean and standard deviation values of calibration coefficients A and B of different anemometers calibrated using the AC procedure at the IDR/UPM Institute between January 2003 and July 2007.

\begin{tabular}{|c|c|c|c|c|c|c|c|}
\hline Anemometer & $n$ & $A(m e a n)$ & $\sigma_{\mathrm{A}}\left(\times 10^{4}\right)$ & $B$ (mean) & $\sigma_{\mathrm{B}}\left(\times 10^{2}\right)$ & $R^{2}$ (mean) & $A_{r}$ (mean) \\
\hline NRG Maximum 40/40C & 571 & 0.770 & 40.58 & 0.324 & 4.17 & 0.99998 & 1.534 \\
\hline NRG Maximum $40 \mathrm{H}$ & 6 & 0.772 & 60.29 & 0.313 & 1.35 & 0.99999 & 1.545 \\
\hline NRG IceFree & 103 & 0.610 & 89.76 & 0.496 & 9.23 & 0.99962 & 1.221 \\
\hline RISØ P2546A & 83 & 0.627 & 33.17 & 0.179 & 1.77 & 0.99999 & 1.255 \\
\hline Thies 4.3350 & 874 & 0.0483 & 1.93 & 0.248 & 2.47 & 0.99999 & 1.786 \\
\hline Thies 4.3303 & 196 & 0.0470 & 5.83 & 0.499 & 10.12 & 0.99998 & 2.067 \\
\hline Thies 4.3520 & 22 & 0.0850 & 7.64 & 0.442 & 5.32 & 0.99999 & 0.850 \\
\hline Thies 4.3324 & 10 & 0.0464 & 4.22 & 0.567 & 4.12 & 0.99999 & 2.043 \\
\hline Thies 4.3519 & 3 & 0.0763 & 10.66 & 0.483 & 8.49 & 0.99999 & 0.839 \\
\hline Climatronics 100075 & 35 & 0.0473 & 3.06 & 0.208 & 2.85 & 0.99997 & 1.419 \\
\hline Vector Inst. A100 L2 & 189 & 0.0505 & 3.27 & 0.184 & 2.86 & 0.99998 & 1.263 \\
\hline Vector Inst. A100 L2 & 13 & 29.742 & 4015.41 & 0.382 & 7.45 & 0.99998 & - \\
\hline Vector Inst. A100 K & 23 & 0.0503 & 3.76 & 0.181 & 2.56 & 0.99999 & 1.257 \\
\hline Vector Inst. A100 LK & 167 & 0.0505 & 3.62 & 0.195 & 2.83 & 0.99998 & 1.262 \\
\hline Vector Inst. A100 LM & 17 & 0.0974 & 5.02 & 0.186 & 2.56 & 0.99999 & 1.266 \\
\hline Vector Inst. A100 R & 27 & 1.220 & 108.66 & 0.175 & 3.36 & 0.99998 & 1.220 \\
\hline Vector Inst. A100 M & 3 & 0.0972 & 5.86 & 0.148 & 4.57 & 0.99997 & 1.263 \\
\hline Ornytion 107 & 77 & 0.624 & 47.01 & 0.215 & 2.48 & 0.99998 & 1.248 \\
\hline RM Young 3002 & 87 & 0.755 & 59.65 & 0.372 & 6.17 & 0.99999 & 0.755 \\
\hline RM Young $3002 \mathrm{VM}^{a}$ & 77 & 50.207 & 4640.68 & 0.343 & 7.68 & 0.99999 & - \\
\hline RM Young 3102 & 2 & 0.748 & 36.33 & 0.403 & 0.95 & 1.00000 & 0.748 \\
\hline RM Young $3102 \mathrm{VM}^{\mathrm{a}}$ & 35 & 50.435 & 3455.66 & 0.378 & 5.99 & 0.99999 & - \\
\hline RM Young 05103 & 153 & 0.0992 & 4.36 & 0.148 & 2.62 & 0.99999 & - \\
\hline RM Young $27106 T^{a}$ & 15 & 18.008 & 1220.86 & 0.028 & 2.03 & 0.99998 & - \\
\hline Vaisala WAA 151 & 4 & 0.0995 & 3.88 & 0.305 & 3.71 & 0.99998 & 1.393 \\
\hline Vaisala WAA 252 & 9 & 0.104 & 10.13 & 0.213 & 2.33 & 0.99998 & 1.456 \\
\hline Orbital 420 & 28 & 0.184 & 7.40 & 0.614 & 3.41 & 0.99999 & 1.106 \\
\hline
\end{tabular}

The table also shows the number of calibrations taken into account for these statistics $n$ the mean value of the square of the correlation coefficient between the data and the linear fitting $R^{2}$ and coefficient $A$ based on the anemometer's rotation frequency $A_{r}$ (only for cup anemometers and frequency output). The values refer to new, not used, anemometers.

${ }^{a}$ In these cases, the calibrations were carried out taking the voltage output instead of the frequency output.

Table V. Mean and standard deviation values of calibration coefficients, A and B, of different anemometers calibrated using the AD procedure at the IDR/UPM Institute between January 2003 and July 2007.

\begin{tabular}{|c|c|c|c|c|c|c|}
\hline Anemometer & $n$ & $A$ (mean) & $\sigma_{A}\left(\times 10^{4}\right)$ & $\mathrm{B}$ (mean) & $\sigma_{\mathrm{B}}\left(\times 10^{2}\right)$ & $R^{2}$ (mean) \\
\hline NRG Maximum 40/40C & 553 & 0.764 & 41.61 & 0.350 & 4.79 & 0.99998 \\
\hline NRG IceFree & 93 & 0.587 & 157.99 & 0.505 & 20.50 & 0.99983 \\
\hline RISø P2546A & 36 & 0.629 & 16.53 & 0.165 & 1.63 & 1.00000 \\
\hline Thies 4.3350 & 71 & 0.0484 & 3.31 & 0.245 & 4.45 & 0.99998 \\
\hline Thies 4.3303 & 12 & 0.0466 & 3.50 & 0.578 & 3.81 & 1.00000 \\
\hline Thies 4.3520 & 19 & 0.0842 & 5.51 & 0.492 & 6.77 & 0.99997 \\
\hline Vector Inst. A100 L2 & 23 & 0.0503 & 2.13 & 0.203 & 2.63 & 0.99999 \\
\hline Vector Inst. A100 K & 27 & 0.0504 & 4.73 & 0.179 & 3.12 & 0.99999 \\
\hline Vector Inst. A100 LK & 6 & 0.0506 & 2.10 & 0.187 & 2.85 & 0.99999 \\
\hline Ornytion 107 & 18 & 0.620 & 22.21 & 0.193 & 3.30 & 0.99999 \\
\hline RM Young 3002 & 16 & 0.751 & 28.97 & 0.476 & 5.53 & 0.99999 \\
\hline RM Young $3002 V^{V^{a}}$ & 5 & 50.027 & 2566.52 & 0.415 & 4.85 & 0.99998 \\
\hline RM Young 3102 & 5 & 0.742 & 17.15 & 0.482 & 2.99 & 0.99998 \\
\hline RM Young $3102 \mathrm{VM}^{a}$ & 4 & 49.528 & 977.03 & 0.462 & 4.61 & 0.99998 \\
\hline RM Young 05103 & 161 & 0.0994 & 4.66 & 0.133 & 2.69 & 0.99999 \\
\hline
\end{tabular}

The table also shows the number of calibrations taken into account for these statistics $n$ and the mean value of the square of the correlation coefficient between the data and the linear fitting $R^{2}$. The values refer to new, not used, anemometers.

${ }^{a}$ In these cases, the calibrations were carried out taking the voltage output instead of the frequency output. 

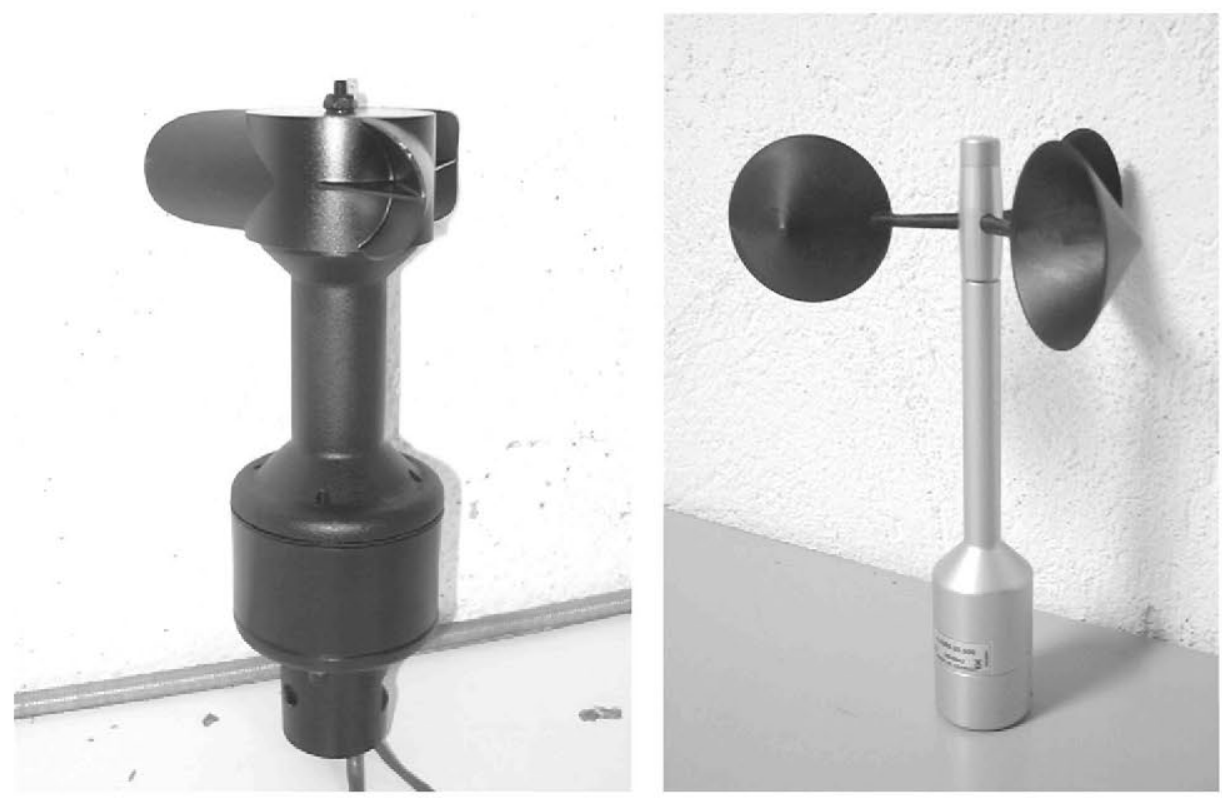

Figure 7. NRG IceFree anemometer (left) and Thies 4.3350 anemometer.

frequency opto-electronically (squared output wave). No correlation with the cup shape (conical or spherical) is observed in Figure 8.

As shown in Figure 8, A-coefficient values from different cup anemometers do not seem directly comparable because the output frequency depends on both the anemometer's rotation frequency $f_{r}$ and the number of pulses per rotation given by the anemometer $N_{p}$, which differs from one model to another (see Table I). However, it is possible to make such a comparison if the calibration curves are expressed as a function of the anemometer's rotation frequency using expression (2).

The $\mathrm{A}_{r}$ calibration coefficient values of the cup anemometers studied are shown in Figure 9 as a function of both the cup rotation radius $R_{r c}$ and the front area of the cups $S_{c}$ (see also Table IV). Regression lines fitted to the data are also included in Figure 9. There seems to be a linear behavior of the calibration coefficient based on the anemometer's rotation frequency $\mathrm{A}_{r}$ with both parameters $R_{r c}$ and $S_{c}$, although in the case of the cup center rotation radius, statistical confidence in the linear fitting is not high $\left(R^{2}=0.485\right)$. However, this regression coefficient improves if only similarly shaped anemometers are taken into account. The ratio of the rotor diameter to the cup diameter $\phi$ of the selected anemometers is plotted as a function of the cup center rotation radius $R_{r c}$ in Figure 10. It can be observed that Thies 4.3324, Thies 4.3303 and RM Young 3002/3102 differ from the other models as their shape parameter $\phi$ is larger. If the aforementioned anemometers are not taken into account, the regression line concerning the dependence of $\mathrm{A}_{r}$ calibration coefficients on the cup rotation radius $R_{r c}$ fits the data significantly better, with a larger regression coefficient, $R^{2}=0.753$ (this new regression line is also indicated in Figure 9 (a) as a dashed line).

Regarding the influence of the front area of the cups $S_{c}$ on $\mathrm{A}_{r}$ calibration coefficients, the opposite is shown. When the four anemometers mentioned earlier are not taken into account, the fit between the regression line and the data is worse as the regression coefficient is reduced from $R^{2}=0.664$ to $R^{2}=0.326$ (the new regression line is indicated in Figure 9 (b) as a dashed line). This suggests that the effect of the front area of the cups $S_{c}$ as a parameter on the $\mathrm{A}_{r}$ calibration coefficient is less important than the effect of the cup center rotation radius $R_{r c}$.

In order to show an explanation for the linear relationship between $\mathrm{A}_{r}$ and $R_{r c}$, a simple two-cup model is considered (see Figure 11). The equation that describes the behavior of the anemometer at a constant wind speed $V$ is:

$$
F_{1}=F_{2}
$$

where $F_{1}$ and $F_{2}$ can be expressed in terms of the aforementioned wind speed $V$, angular velocity $\omega$, cup center rotation radius $R_{r c}$, the front area of the cups $S_{c}$ and the drag coefficients of the cups $c_{d 1}$ and $c_{d 2}$ :

$$
\frac{1}{2} \rho\left(V-\omega R_{r c}\right)^{2} c_{d 1} S_{c}=\frac{1}{2} \rho\left(V+\omega R_{r c}\right)^{2} c_{d 2} S_{c}
$$




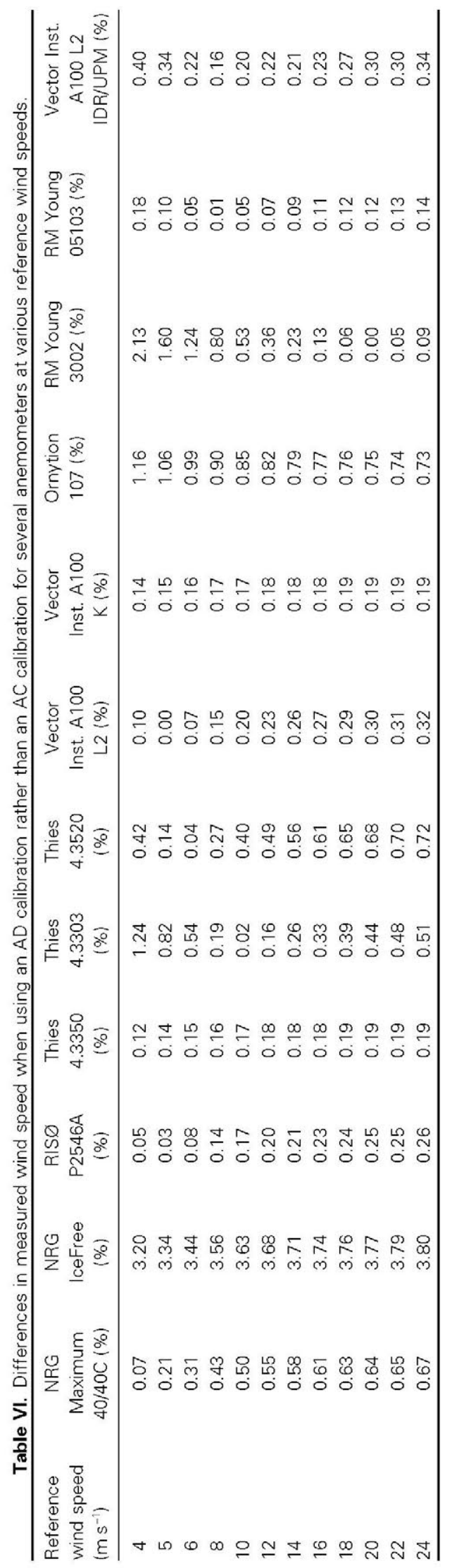


Table VII. Percentage variation in the AEP of a GE2.5 wind turbine, related to the differences in measured wind speed between $A C$ and $A D$ calibration.

\begin{tabular}{lccr}
\hline Anemometer & \multicolumn{3}{c}{ Hub height annual average wind speed (\%) } \\
\cline { 2 - 4 } & 4 & 7 & 10 \\
\hline NRG Maximum 40/40C & 0.91 & 0.45 & 0.25 \\
NRG IceFree & 4.53 & 1.99 & 1.07 \\
RIS $\varnothing$ P2546A & 0.67 & 0.32 & 0.18 \\
Thies 4.3350 & 0.75 & 0.34 & 0.19 \\
Thies 4.3303 & 1.29 & 0.42 & 0.21 \\
Thies 4.3520 & 0.82 & 0.39 & 0.22 \\
Vector Inst. A100 L2 & 0.68 & 0.32 & 0.18 \\
Vector Inst. A100 K & 0.77 & 0.34 & 0.19 \\
Ornytion 107 & 1.75 & 0.72 & 0.38 \\
RM Young 3002 & 2.12 & 0.72 & 0.37 \\
RM Young 05103 & 0.67 & 0.28 & 0.15 \\
\hline
\end{tabular}

(a)

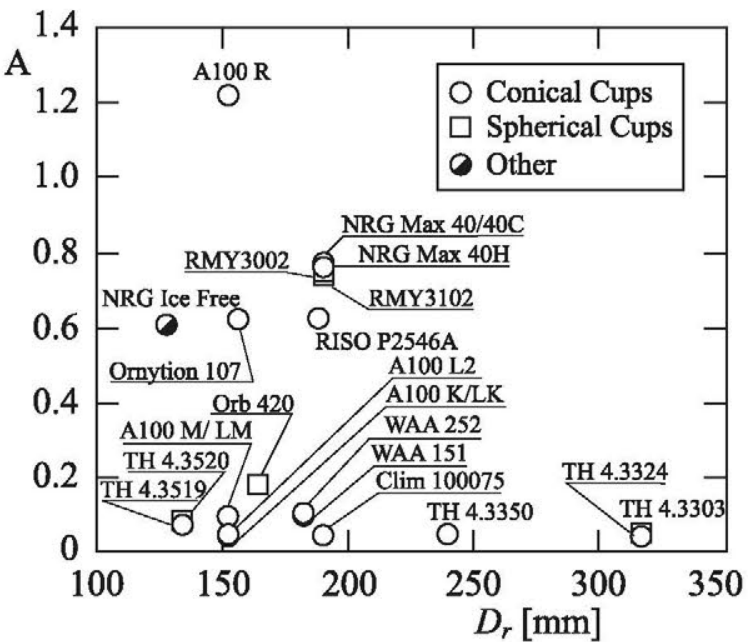

(b)

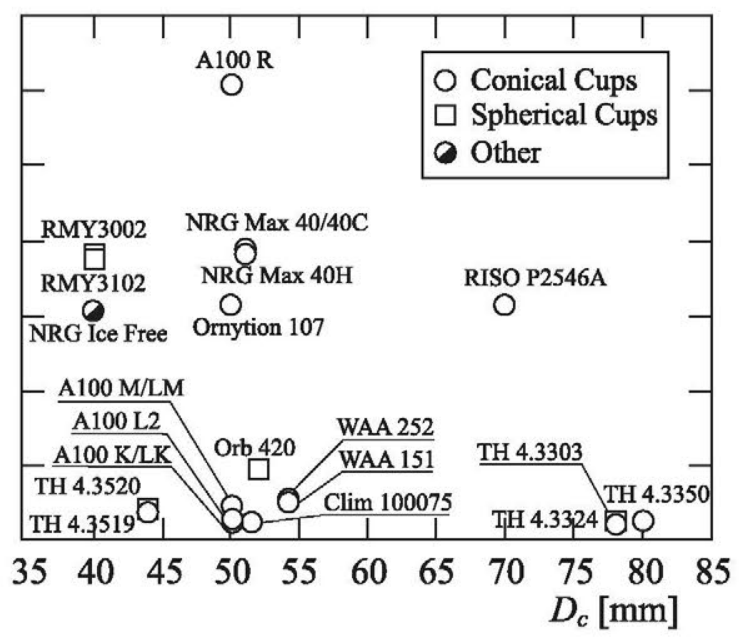

Figure 8. Mean values of calibration coefficient $A$ for the cup anemometers studied as a function of the anemometer rotor diameter $D_{r}(\mathrm{a})$ and the anemometer cup diameter $D_{c}(\mathrm{~b})$.

This equation can be simplified in order to obtain the wind speed as a function of the anemometer's rotation frequency $f_{r}$ :

$$
V=2 \pi\left(\frac{k_{d}+1}{k_{d}-1}\right) R_{r c} f_{r}
$$

where $k_{d}$ is:

$$
k_{d}=\sqrt{\frac{c_{d 1}}{c_{d 2}}}
$$

Standard drag coefficient values for spherical cups $\left(c_{d 1}=1.4 \text { and } c_{d 2}=0.4\right)^{11}$ result in the following expression for the ideal behavior of a 'generic cup anemometer' (no friction is considered, not to mention the aerodynamic effects of the cups' wake, and the two-cup idealization of a three-cup anemometer):

$$
V=20.7 R_{r c} f_{r}
$$

The aforementioned equation leads to an estimated expression of $\mathrm{A}_{r}$ as a function of the cup center rotation radius $R_{r c}$ :

$$
\mathrm{A}_{r}=20.7 R_{r c}
$$


(a)

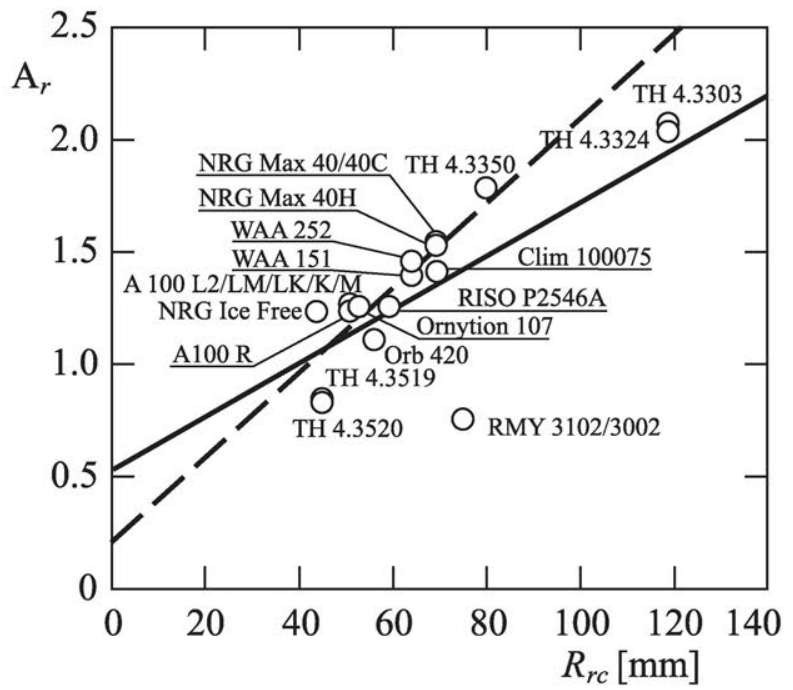

(b)

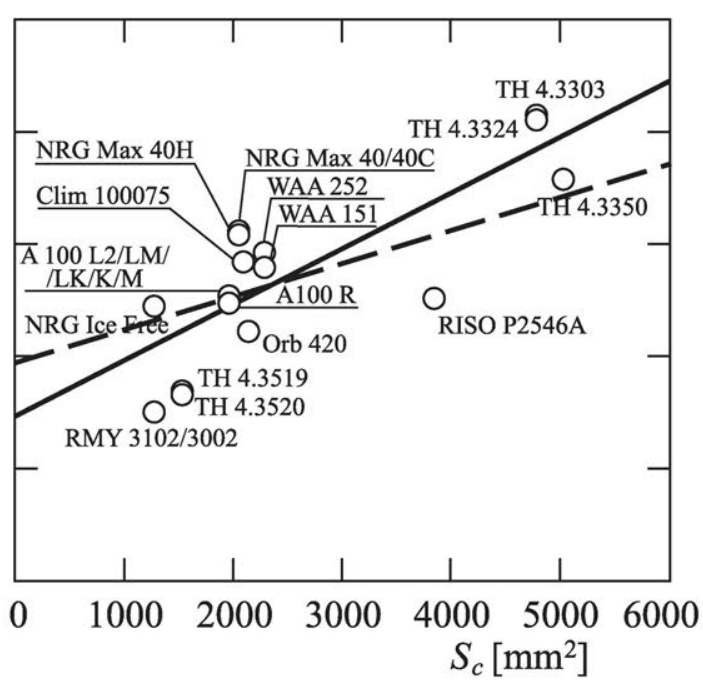

Figure 9. Mean values of calibration coefficient $\mathrm{A}$, for the cup anemometers studied as a function of the cup rotation radius $R_{r c}$ (a) and the front area of the cups $S_{c}$ (b). The fitted lines on the left side are: $A_{r}=0.012 R_{r c}+0.546, R^{2}=0.485$ (solid line, fitted to all data points), and $A_{r}=0.019 R_{r c}+0.196, R^{2}=0.753$ (dashed line, fitted to all data points except TH 4.3324/4.3303 and RMY 3102/3002); on the right side: $A_{r}=0.00025 S_{c}+0.73717, R^{2}=0.664$ (solid line, fitted to all data points), and $A_{r}=0.00015 S_{c}+$ $0.96708, R^{2}=0.326$ (dashed line, fitted to all data points except TH 4.3324/4.3303 and RMY 3102/3002).

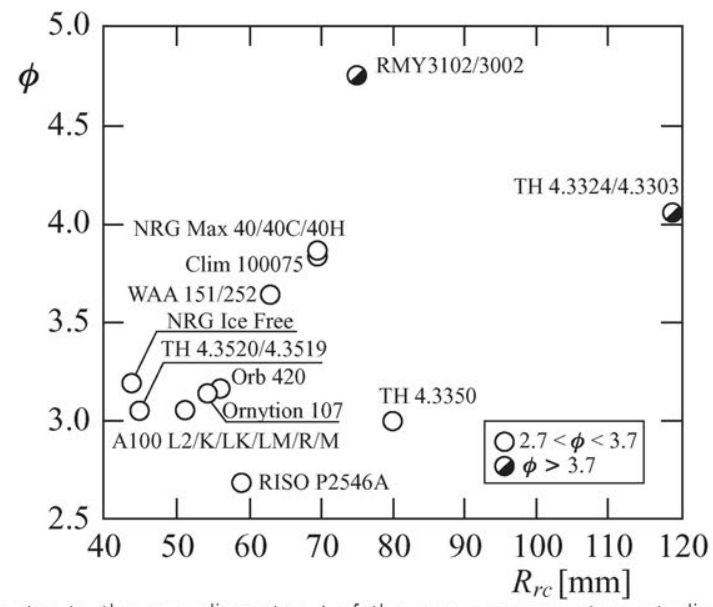

Figure 10. Ratio of the rotor diameter to the cup diameter $\phi$ of the cup anemometers studied as a function of the cup rotation radius $R_{\text {rc }}$.

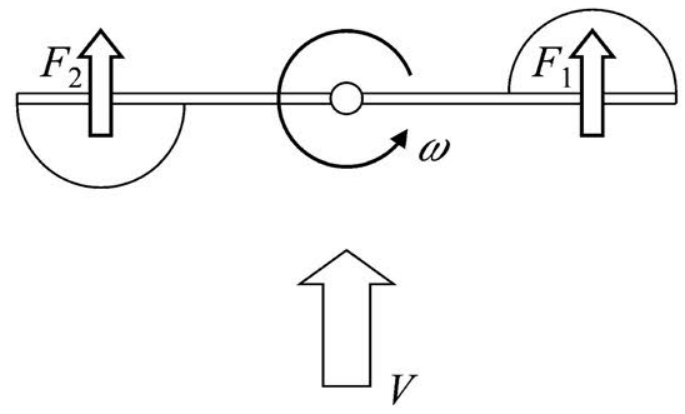

Figure 11. Sketch of a two-cup anemometer configuration. The forces on the two cups $F_{1}$ and $F_{2}$, the wind speed $V$ and the angular velocity $\omega$ are indicated. 
(a)

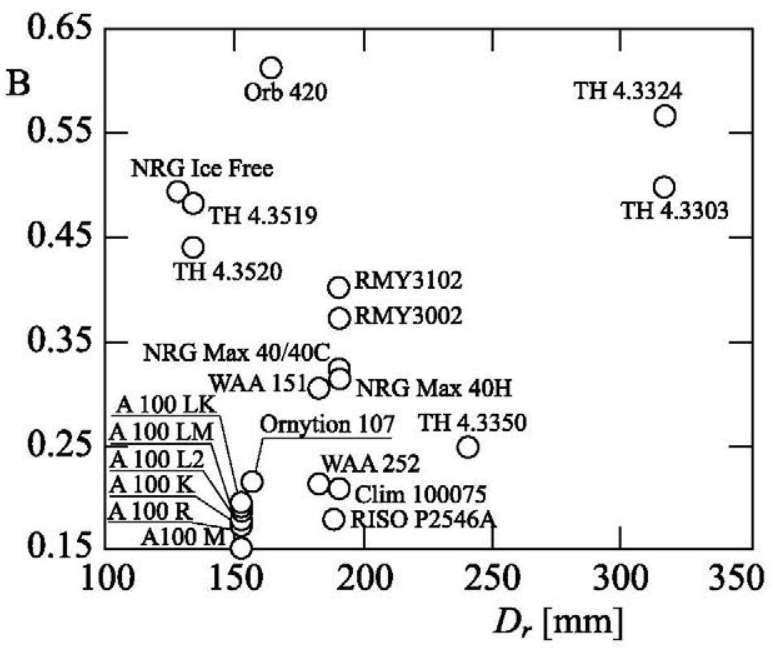

(b)

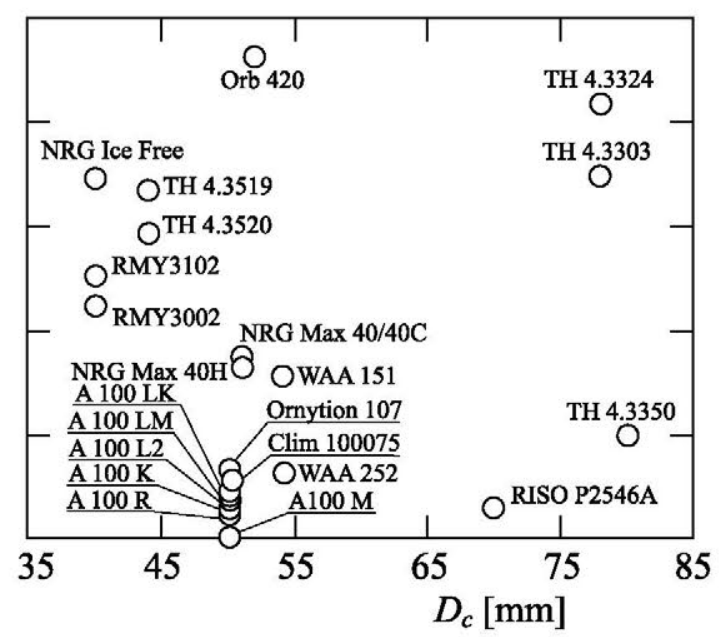

Figure 12. Mean values of calibration coefficient $B$ for the cup anemometers studied as a function of the anemometer rotor diameter $D_{r}(\mathrm{a})$ and the anemometer cup diameter $D_{c}(b)$.

in which the slope 20.7 is significantly close to the slope of the fitted line to the data in Figure 9(a), excluding the nonsimilar-shaped anemometers (dashed line) $\mathrm{A}_{r}=19 R_{r c}+0.196\left(R_{r c}\right.$ expressed in meters). Finally, equation (7) shows that the $\mathrm{A}_{r}$ calibration coefficient does not depend directly on the front area of the cups $S_{c}$. If some dependence appears, it is not direct as the effect of this parameter on $\mathrm{A}_{r}$ is less important than the effect of the cup center rotation radius $R_{r c}$.

The B coefficient of calibration curves (1) and (2) is called the offset speed or starting speed of the anemometer. However, it does not represent the wind speed that causes the anemometer to start to rotate as the contribution of the friction from the bearings is comparable with the aerodynamic forces at very low wind speeds. ${ }^{2}$ The values of coefficient $\mathrm{B}$ corresponding to $\mathrm{AC}$ calibrations of cup anemometers (frequency output) are shown as a function of the rotor diameter $D_{r}$ and cup diameter $D_{c}$ in Figure 12. No correlation has been observed between the values of this coefficient and the two parameters with the exception of the agglomeration of the data for different anemometer models by the same manufacturer (Vector Instruments, RM Young, Thies).

\section{CONCLUSIONS}

In this study, the anemometer calibrations carried out at the IDR/UPM Institute between January 2003 and August 2007 were analysed to find some correlation between the calibration coefficients and the geometrical parameters. The major conclusions resulting from this work are:

- No large differences in terms of wind speed and AEP have been found for a calibration procedure different from the one required by MEASNET (fewer points, i.e. nine rather than 14 and a larger wind speed range, from $4 \mathrm{~m} \mathrm{~s}^{-1}$ to $23 \mathrm{~m} \mathrm{~s}^{-1}$ instead of $4 \mathrm{~m} \mathrm{~s}^{-1}$ to $\left.16 \mathrm{~m} \mathrm{~s}^{-1}\right)$.

- There seems to be a correlation between the slope $\mathrm{A}_{r}$ of a cup anemometer calibration curve (based on the rotation frequency) and the cup center rotation radius $R_{r c}$. With the present results, no conclusion in this sense can be made regarding the front area of the cups $S_{c}$ as no clear correlation has been found between this parameter and $\mathrm{A}_{r}$.

\section{ACKNOWLEDGEMENTS}

The authors would like to thank Jesús López (Geonica), Alfonso Rosende (Ornytion), Scott J. Miller (Climatronics Corp.), Wolfgang W. Meyer (Orbital), Dave Dicks (Vector Instruments), David Carlson (NRG Systems) and Bernd Nasner (Thies Clima) for their kind help in providing us with anemometer specifications.

The authors are grateful to Professor Angel Sanz-Andrés from the IDR/UPM Institute for his useful comments and encouraging support.

The authors are also grateful to the reviewers for their useful comments, which have helped us to improve the text.

Finally, the authors are grateful to Ms. Tania Tate for her kind help in improving the style of the text. 


\section{REFERENCES}

1. López Peña F, Duro RJ. A virtual instrument for automatic anemometer calibration with ANN based supervision. IEEE Transactions on Instrumentation and Measurement 2003; 52: 654-661.

2. Kristensen L. Cup anemometer behavior in turbulent environments. Journal of Atmospheric and Oceanic Technology 1998; 15: 5-17.

3. Kristensen L. Measuring high-order moments with a cup anemometer. Journal of Atmospheric and Oceanic Technology 2000; 17: 1139-1148.

4. Kristensen L. Can a cup anemometer 'underspeed'? Boundary-Layer Meteorology 2002; 103: 163-172.

5. Measuring Network of Wind Energy Institutes (MEASNET). Cup anemometer calibration procedure, Version 1 (1997).

6. Dahlberg J-Å, Pedersen TF, Busche P. ACCUWIND—Methods for Classification of Cup Anemometers. Ris $\phi-$ $R-1555(E N)$. Ris $\varnothing$ National Laboratory: Roskilde, 2006.

7. Schrenk O. Über die trägheitsfehler des schalenkreuz-anemometers bei schwankender windstärke. Zeitschrift für Technische Physik 1929; 10: 57-66.

8. Ramachandran S. A theoretical study of cup and vane anemometers. Quarterly Journal of the Royal Meteorological Society 1969; 95: 163-180.

9. Measuring Network of Wind Energy Institutes (MEASNET). Statement about anemometer calibration. September 2009. [Online]. Available: http://www.measnet.com. (Accessed 3 March 2010)

10. International Standard IEC-61400-12-1. Wind turbines. Part 12-1: Power performance measurements of electricity producing wind turbines. First edition, 2005-12.

11. Brevoort MJ, Joyner UT. Aerodynamic characteristics of anemometer cups. National Advisory Committee For Aeronautics. Washington, USA 1934. 